\title{
New concepts for translational head and neck oncology: lessons from HPV-related oropharyngeal squamous cell carcinomas
}

\author{
Efterpi Kostareli ${ }^{1}$, Dana Holzinger ${ }^{2}$ and Jochen Hess ${ }^{1,3} *$ \\ Department of Otolaryngology, Head and Neck Surgery, Research Group Experimental Head and Neck Oncology, University Hospital Heidelberg, Heidelberg, \\ Germany \\ 2 Division of Genome Modifications and Carcinogenesis (F020), Infection and Cancer Program, German Cancer Research Center, Heidelberg, Germany \\ 3 Junior Group Molecular Mechanisms of Head and Neck Tumors (A102), DKFZ-ZMBH Alliance, German Cancer Research Center, Heidelberg, Germany
}

Edited by:

Seungwon Kim, University of

Pittsburgh School of Medicine, USA

\section{Reviewed by:}

Herbert Loong, Prince of Wales

Hospital, Hong Kong

Guilherme Rabinowits, Dana-Farber

Cancer Institute, USA

\section{*Correspondence:}

Jochen Hess, Department of Otolaryngology, Head and Neck

Surgery, Experimental Head and Neck Oncology, University Hospital Heidelberg, Im Neuenheimer Feld 400, D-69120 Heidelberg, Germany. e-mail: jochen.hess@med.uniheidelberg.de
Human papillomavirus (HPV) infection is well established as an etiological agent responsible for a number of pathologies affecting the stratified epithelia of skin and anogenital sites. More recently, the infection by (mucosal) high-risk HPV types has also been found to be causally associated with squamous cell carcinoma in the head and neck region (HNSCC), especially in the oropharynx. Intriguingly, HPV-related oropharyngeal squamous cell carcinomas (OPSCC) represent a distinct clinical entity compared to HPV-negative tumors with particular regard to treatment-response and survival outcome. The association between HPV infection and OPSCC may therefore have important implications for the prevention and/or treatment of OPSCC. The improved survival of patients with HPV-related tumors also raises the question, as to whether a better understanding of the underlying differences may help to identify new therapeutic concepts that could be used in targeted therapy for HPVnegative and improved therapy for HPV-positive cancers. This review summarizes the most recent advances in our understanding of the molecular principles of HPV-related OPSCC, mainly based on functional genomic approaches, but also emphasizes the significant role played by the tumor microenvironment, especially the immune system, for improved clinical outcome and differential sensitivity of HPV-related tumors to current treatment options.

Keywords: HNSCC, HPV, OPSCC, epigenome, genome, transcriptome

\section{HPV INFECTION IN THE PATHOGENESIS AND PROGNOSIS OF HNSCC}

Head and neck squamous cell carcinoma (HNSCC) is one of the most prevalent and lethal cancers worldwide (Argiris et al., 2008). Despite recent advances in early detection, surgical techniques, radiation and chemotherapeutic regimes (Temam et al., 2007; Sheu et al., 2009), the survival rate and quality of life for patients with HNSCC has only marginally improved over the past few decades (Haddad and Shin, 2008; Masuda et al., 2011). There is a desperate need for better biomarkers, to identify patients at high-risk for treatment failure, as well as novel concepts for a more effective and less toxic therapy for patients with advanced tumors (Hunter et al., 2005; Leemans et al., 2011).

Head and neck squamous cell carcinoma has a strong epidemiologic background (Rodriguez et al., 2004; D’Souza et al., 2007; Furniss et al., 2009) including environmental and lifestyle factors. The major risk factors for HNSCC are tobacco and alcohol abuse; however, the escalating incidence of oropharyngeal carcinoma (oropharyngeal squamous cell carcinoma, OPSCC) are not explained by increases in either smoking and alcohol consumption suggesting that atypical behavioral and environmental factors are also involved (Ernster et al., 2007). Importantly, a subgroup of OPSCCs has causally been linked to infection with high-risk types of human papillomavirus (HPV), especially HPV16 (Gillison et al.,
2008; Pai and Westra, 2009). HPV infection has been established as a causative agent for almost $70 \%$ of OPSCCs and $20-25 \%$ of all HNSCCs (Gillison et al., 2000; Begum et al., 2005; Kreimer et al., 2005; Reimers et al., 2007; Hoffmann et al., 2010). In recent years, HPV-related tumors have been shown to be a new tumor entity in itself, with distinct clinical and histopathological features, including younger median age, oropharyngeal primary anatomical site, small tumor size, high lymph node involvement, as well as a lack of typical risk factors, and increasing incidence over the last decades at variance with decreasing total HNSCC incidence. Furthermore, HPV-related tumors do not show significant keratinization and they have a prominent basaloid morphology. The differences between HPV-related and HPV-negative tumors have been reviewed in several excellent recent reviews (Argiris et al., 2008; Psyrri and Dimaio, 2008; Leemans et al., 2011).

Intriguingly, patients with a HPV-positive tumor have improved performance status and a better prognosis compared to HPV-negative patients, even though the former patients were more likely to present with regional lymph node metastasis at the time of diagnosis (Curado and Hashibe, 2009; Pai and Westra, 2009). In general, HPV-positive patients are highly curable with ionizing radiation with or without chemotherapy, and have better overall and disease-free survival compared to patients diagnosed with HPV-negative tumors (Figure 1) (Fakhry et al., 2008; 


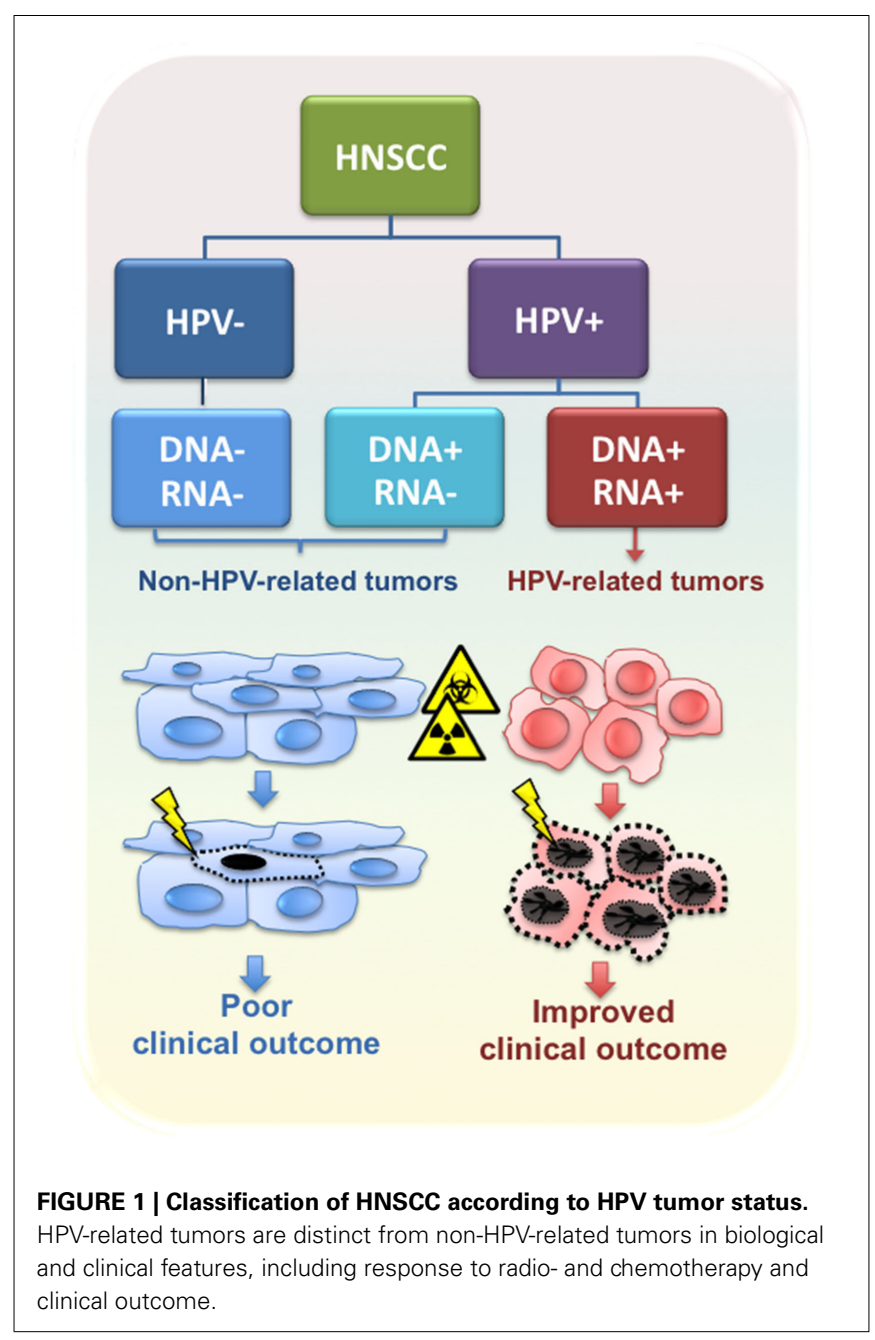

Ang et al., 2010). However, in several studies HPV DNA-positive OPSCCs were heterogeneous in both biological and clinical behavior, possibly due to differences in viral load and/or viral oncogene expression (Paz et al., 1997; Andl et al., 1998; Klussmann et al., 2001; van Houten et al., 2001; Mellin et al., 2002; Wiest et al., 2002; Braakhuis et al., 2004; Lindquist et al., 2007; Reimers et al., 2007; Attner et al., 2010; Jung et al., 2010).

\section{ALTERATIONS IN THE GENOME, EPIGENOME, AND TRANSCRIPTOME OF HPV-RELATED TUMORS}

Functional genome and transcriptome studies strongly suggest that HPV-related HNSCCs comprise a disease entity that differs from HPV-negative tumors in regard to distinct molecular characteristics. In the past, several groups used comparative genomic hybridization $(\mathrm{CGH})$ to identify genomic imbalance in the pathogenesis of HNSCCs, focusing on HPV-related and HPV-negative tumors (Dahlgren et al., 2003; Smeets et al., 2006; Klussmann et al., 2009; Wilting et al., 2009). Despite tumor-associated genomic alterations, which are common in both groups, these studies highlighted that per tumor, the total amount of chromosomal alterations, as well as amplifications was significantly lower in the HPV-related than in the HPV-unrelated tumors (Table 1). This
Table 1 | Alteration in the genome of HNSCCs: genomic aberrations characteristic for HPV-related OPSCC.

\begin{tabular}{ll} 
HPV-dependent genomic aberration & Reference \\
\hline $3 p 25,9 p 21,11 q 13$, and 16q12-24 & Jung et al. (2010) \\
$3 p, 5 q, 8 p, 11 q, 13 q$, and $20 q$ & Wilting et al. (2009) \\
$3 p, 5 q, 9 p, 11 q 13,15 q, 16 q, 18 q$, and Xp & Klussmann et al. (2009) \\
$3 p 11.2-26.3,5 q 11.2-35.2,9 p 21.1-24$, & Smeets et al. (2006) \\
11q12.1-13.4, and 18q12.1-23 & \\
$3 q 24-q t e r$ and 7q11.2-q22 & Dahlgren et al. (2003) \\
\hline
\end{tabular}

finding is consistent with the assumption that due to the inactivation of the tumor suppressor proteins $\mathrm{p} 53$ and $\mathrm{pRb}$ by the viral E6 and E7 oncoproteins, respectively, the number of required genetic alterations for a malignant phenotype is lower in HPVrelated carcinogenesis. Consequently, a better clinical outcome of patients with HPV-related tumors could simply be a reflection of less genetic aberrations at the time of treatment. However, specific HPV-related genetic alterations have also been identified (Table 1) some of which were connected with improved survival. For example, 16q loss, which was predominantly identified in HPV-related OPSCC, was a strong indicator of favorable outcome and none of these patients had a tumor recurrence (Klussmann et al., 2009). Additionally, HPV-negative tumors demonstrate a loss at 18q12.123, in contrast to a gain in HPV-positive tumors (Smeets et al., 2006). It will be a major challenge in the future to identify candidate genes at the affected genomic sites, and to investigate their contribution to treatment resistance and tumor cell survival in both patient cohorts as well as preclinical model systems.

To uncover the genetic origin and the mutational landscape of HNSCC, two recent studies applied gene copy number and whole exome sequence analysis on specimens of tumor-normal pairs, including samples from patients with HPV-related tumors (Agrawal et al., 2011; Stransky et al., 2011). In both studies, the majority of tumors exhibited a mutational profile consistent with tobacco exposure, and there were obvious differences in the genetic landscapes of HPV-related and HPV-negative HNSCCs. For instance, tumors that were negative for HPV had more mutations than HPV-positive tumors, independently of the smoking status. This finding is in line with the data derived by CGH analysis and further confirms major differences in the pathogenesis of HPV-related and HPV-negative tumors. Furthermore, both studies observed an inverse correlation between the HPV status and TP53 mutations, as already shown previously (Wiest et al., 2002; Westra et al., 2008).

In addition to genomic alteration and gene mutation, aberrant DNA methylation is widely recognized as a mechanism in the progression of HNSCC (Hasegawa et al., 2002; Schmezer and Plass, 2008), but our knowledge on virus-induced changes in DNA methylation of the host genome as well as other modes of epigenetic alterations, as part of the divergent carcinogenic pathway, is limited. Nevertheless, the identification of distinct epigenetic profiles in HPV-related and HPV-negative tumors should provide clues to novel drug targets for development of individualized therapeutic strategies. Currently, there is a limited number of studies which address the differences in epigenetic alteration between 
HPV-related and HPV-negative tumors. Furthermore, the published data has largely evaluated changes in promoter methylation of a limited number of candidate genes, most of which were selected based on functional relevance in several human malignancies (Table 2). A more recent study by Sartor et al. (2011) applied an integrative approach combining genome-wide methylation and gene expression profiling to characterize the molecular differences between HPV-related and HPV-negative tumor cell lines. They found a higher overall DNA methylation in HPV-positive compared to HPV-negative cell lines. This HPV-dependent difference was consistent with findings in primary tumor samples and in line with data from Richards et al. (2009). Moreover, an inverse correlation between gene promoter methylation and expression of affected genes was found in HPV-positive cells (Sartor et al., 2011). Although differentially methylated loci found in tumor cell lines were significantly correlated with primary tumor DNA methylation levels, a recent study demonstrated major changes in the DNA methylation pattern between cultured cells and primary tumors (Hennessey et al., 2011). Although these findings may direct alterations in the epigenome to different disease pathways involved in HPV-related versus HPV-negative tumors, critical validation in larger HNSCC tumor sample sets is required.

Global gene expression profiling comparing HPV-related and HPV-negative tumors revealed distinct transcriptome signatures, reflecting underlying heterogeneous somatic, genetic, and epigenetic alterations. As it would have been expected, all published studies identified differentially expressed genes that regulate DNA replication and cell cycle progression (Slebos et al., 2006; Martinez et al., 2007; Pyeon et al., 2007; Lohavanichbutr et al., 2009), while some also describe aberrant regulation of genes involved in viral defense and immune response (Schlecht et al., 2007; Jung et al., 2010). It is worth to mention that some differentially expressed genes are already known to modulate resistance to radiation and chemotherapeutic drugs, but experimental evidence of their impact on the favorable outcome of patients with HPV-related tumors are still missing. Moreover, dysregulation of genes associated with processes of Natural Killer Cell-mediated cytotoxicity, activation of the Toll-like receptor, JAK-STAT signaling pathways (Jung et al., 2010), as well as immune response and inflammation (Schlecht et al., 2007), are of particular interest, assumpting that the mechanisms underlying the clinical differences of HPV-related and HPV-negative tumors may involve the combined effects of immune surveillance to viral-specific tumor antigens, an intact apoptotic response to radiation, and the absence of widespread genetic alterations (Pai and Westra, 2009). Yet, the correlation between altered cytokine and interferon signaling and the HPV status further supports the conclusion that improved survival of patients with HPV-related tumors may not only depend on tumor cell intrinsic features, but also could be due to different activation of stromal cells within the tumor microenvironment (Figure 2).

MicroRNAs (miRNAs) are small non-coding RNAs, which represent another mode of gene regulation by influencing mRNA translation or decay. Several studies reported altered expression of distinct miRNAs in the pathogenesis of HNSCC (Babu et al., 2011). Two recent studies characterized the influence of HPV on global miRNA expression in HNSCC cell lines (Wald et al., 2011), and tumor biopsies of HNSCC patients (Lajer et al., 2011), respectively. Although, the overlap on common deregulated miRNAs is

Table 2 | Summary of genes affected by DNA methylation in HNSCC.

\begin{tabular}{|c|c|c|c|c|}
\hline Study & Genes/proteins & $\mathbf{T}$ & CL & HPV \\
\hline El-Naggar et al. (1997) & CDKN2A & 46 & 11 & - \\
\hline Hasegawa et al. (2002) & CDKN2A, DAPK, ECAD, RASSF1A & 80 & - & \\
\hline Dong et al. (2003) & RASSF1A & 46 & 7 & + \\
\hline Wong et al. (2003) & CDKN2B, CDKN2A & 73 & - & - \\
\hline Puri et al. (2005) & MLH1, MGMT, CDKN2A & 51 & - & - \\
\hline Marsit et al. (2006) & SFRP family & 350 & & + \\
\hline Weber et al. (2005) & SOCS-1, SOCS-3 & 94 & - & - \\
\hline Dikshit et al. (2007) & MGMT, DAPK, E-cadherin & 235 & - & - \\
\hline Kim et al. (2007) & CDKN2A, BIRC5, HIF1A, SKP1, CCNA, CCNB, c-myc, EGFR & 52 & - & + \\
\hline Martone et al. (2007) & MGMT, CDKN2A, DAPK & 20 & - & - \\
\hline Righini et al. (2007) & $\begin{array}{l}\text { TIMP3, ECAD, FHIT, APC, DCC, hMLH1, THSB1, RAR } 3 \text { S100A9, CDKN2B, CDKN2A, MGMT, DAPK, } \\
\text { ATM, CASP8, RASSF1 }\end{array}$ & 90 & - & - \\
\hline Carvalho et al. (2008) & $\begin{array}{l}\text { DCC, DAPK, TIMP3, ESR, CCNA1, CCND2, MINT1, MINT31, CDH1, AIM1, MGMT, CDKN2A, } \\
\text { PGP9.5, RARB, HIC1, RASSF1A, CALCA, TGFBR2, S100A2, RIZ1, RBM6 }\end{array}$ & 211 & - & - \\
\hline Marsit et al. (2008) & ECAD & 340 & - & + \\
\hline Taioli et al. (2009) & MGMT, CDKN2A, RASSF1A & 88 & - & + \\
\hline Marsit et al. (2009) & 773 genes & 68 & - & - \\
\hline Munoz-Antonia et al. (2009) & TbetaR-I & 50 & - & - \\
\hline Weiss et al. (2011) & TIMP3, CDH1, CDKN2A, DAPK1, TCF21, CD44, MLH1, MGMT, RASSF1A, CCNA1, LARS2, CEBPA & 55 & - & + \\
\hline Sartor et al. (2011) & DNMT3A, CCNA1, CDKN2A, KRT8, RUNX2, IRS, PcG genes & - & 4 & + \\
\hline Gubanova et al. (2012) & SMG-1 & 34 & 2 & + \\
\hline
\end{tabular}

Genes/proteins, specific gene(s) or protein(s; or total number) of genes investigated in each study; T, total number of tumors/patients included in the study; CL, number of different cell lines included in the study; HPV, consideration of HPV status in the study. 


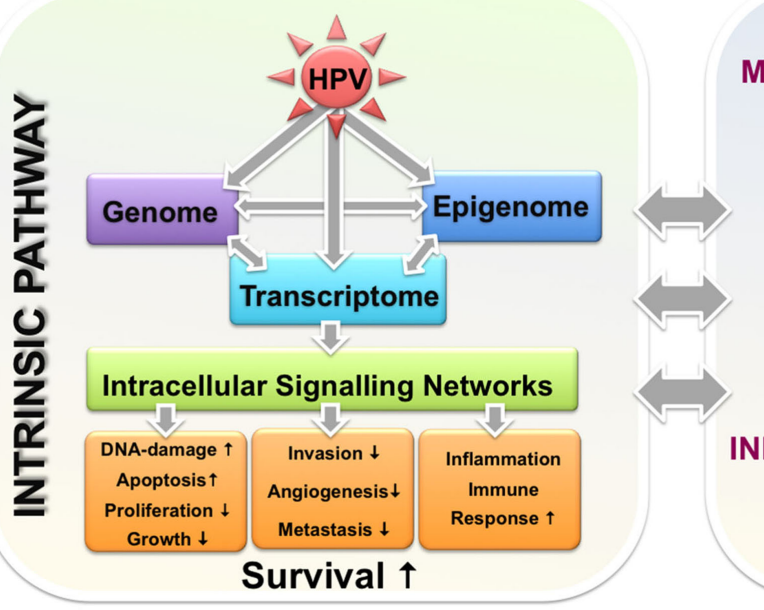

FIGURE 2 | Intrinsic and extrinsic features of HPV-related HNSCC tumors potentially involved in the molecular mechanisms underlying improved disease course. HPV-related tumors have a better survival likely due to the combined effects of phenomena occurring in epigenome, genome, and transcriptome. These events drive alternations in intracellular signaling networks and along with complex interactions of malignant cells with components of tumor microenvironment including immune cells, they orchestrate the improved response to treatment and the favorable outcome. only minor (which may be due to the use of cell lines versus tumor biopsies) increasing our understanding of the virus-targeted miRNAs may provide further insight into molecular mechanisms for the distinct clinical behavior of HPV-related tumors.

\section{CELL INTRINSIC FEATURES OF HPV-POSITIVE TUMOR CELLS}

Several intrinsic hallmarks of tumor cells have been described, including: (i) sustaining proliferative signaling, (ii) evading growth suppressors, (iii) resisting apoptosis, (iv) enabling unlimited replication, (v) inducing angiogenesis, and (vi) activating invasion and metastasis (Hanahan and Weinberg, 2000, 2011). However, which of these capabilities differ between HPV-related and HPV-positive tumor cells and their likely contribution to the differential clinical outcome, is still a matter of debate. For instance, while patients with HPV-related HNSCC respond better to radiotherapy, there is controversial data concerning whether HPV-related tumor cells are indeed inherently more radiosensitive than HPV-negative cells (Pai and Westra, 2009).

Infection by HPV results in over-expression of the viral oncoproteins and thereby affects many cellular pathways as well as genome stability. The oncogenic potential of HPV involves the expression of the viral E6 and E7 oncoproteins, which disrupts the tumor suppressive p53 and pRB signaling pathways, respectively, and thereby modulate cell cycle progression and survival of infected keratinocytes (Zur Hausen, 2002). Continued expression of viral oncogenes is necessary for neoplastic progression and the malignant phenotype of an HPV-associated tumor. Transcriptionally active viral DNA has been shown to be biologically and clinically relevant (Figure 1) (Wiest et al., 2002; Fakhry et al., 2008; Jung et al., 2010). HPV-related HNSCCs have less frequent p53 or pRB mutations, which often occur in HPV-negative tumors (Marur et al., 2010). The tumor suppressor p53 acts as a central mediator of the cellular stress response, including DNA damage induced apoptosis and cellular senescence by chemotherapy and ionizing radiation. Therefore, the presence of wild-type p53 in HPV-related tumors could, at least in part, confer accelerated chemo- and radiosensitivity compared to HPV-negative tumors with p53 mutations. Licitra et al. (2006) found that the clinical behavior of HNSCC patients critically depends on the HPV and the p53 status. They provided clinical evidence that only patients with HPV-related tumors and wild-type p53 exhibit an improved survival, while patients with HPV-related tumors and mutant p53 have an unfavorable outcome, similar to HPV-negative HNSCC patients. However, in a more recent publication Pang et al. (2011) showed that expression of the viral E6 oncogene sensitizes tumor cells to radiation-induced apoptosis, and that the E6* I, and not the E6* II isoform, is sufficient to mediate this effect. Interestingly, E6*I was shown to be a weak inhibitor of p53 transactivator activity, and the study supports a role for $\mathrm{E} 6{ }^{*} \mathrm{I}$ in the enhanced responsiveness of HPV-positive OPSCCs to p53-independent radiation-induced cell death.

The finding that nuclear Survivin is associated with HPVnegative compared to HPV-related OPSCC and correlated with a poor clinical outcome further suggests a fundamental role in cell death regulation (Preuss et al., 2008). Survivin is an inhibitor of apoptosis (IAP) and nuclear Survivin is believed to control cell division, whereas cytoplasmic Survivin is considered cytoprotective (Stauber et al., 2007). HNSCC cases with nuclear Survivin and Aurora-B expression exhibited marked malignant behaviors whereas both Survivin and Aurora-B knockdown inhibited cell growth and tumor formation (Qi et al., 2010). Furthermore, Survivin also plays a critical role in mediating resistance to radiation in part through suppression of apoptosis.

More recently, Gubanova et al. investigated whether the mechanism underlying increased sensitivity of HPV-positive tumors to radiation may be connected to the impaired ability of the cancer cells to respond to DNA damage. They found that expression of SMG-1 (suppressor with morphogenetic effect on genitalia) is 
diminished in HPV-positive tumors due to gene promoter hypermethylation (Gubanova et al., 2012). SMG-1 belongs to a family of phosphoinositide 3-kinase (PI3-kinase)-related kinases (PIKKs) involved in the maintenance of genome integrity via genotoxic stress response pathways and plays an important role in the DNA damage response network (Shiloh, 2003; Brumbaugh et al., 2004; Gewandter et al., 2011). Low SMG expression correlated with positive HPV status and improved patient survival, whereas depletion of SMG-1 in HNSCC cells resulted in their increased sensitivity to radiation (Gubanova et al., 2012).

The impact of HPV E6 and E7 oncoproteins in in vitro cell sensitization to radiation remains controversial, since other studies have suggested that HPV16-positive cervical cancer cells (Padilla et al., 2002) and HNSCC cells (Hoffmann et al., 2008) as well as HPVnegative cells with ectopic E6 and E7 expression (Hampson et al., 2001) are resistant to treatment with cytotoxic drugs and radiation. It is worth noting that increased expression of another IAP molecule, namely CIAP2, was reported to be significantly associated with HPV16-related HNSCCs (Mansour et al., 2012). Viral E6 oncoprotein has been shown to induce CIAP2 expression through either the NF- $\mathrm{B}$ or EGFR/PI3K/AKT signaling pathways. CIAP2 confers less sensitivity to apoptosis in HPV16 E6-immortalized human oral keratinocytes (Yuan et al., 2005; James et al., 2006), and resistance to cisplatin in HPV-infected lung cancer (Wu et al., 2010), or 5-FU treatment of HNSCC cell lines (Nagata et al., 2011). Furthermore, high CIAP2 expression was associated with poor clinical outcome, at least in patients with oral squamous cell carcinoma (Nagata et al., 2011).

\section{IMPACT OF THE IMMUNE SYSTEM}

Although there is a growing body of in vivo and in vitro data supporting the assumption that HPV-related tumors have a better survival due to a higher sensitivity to radiation and chemotherapy, it is difficult to conclusively attribute the improved clinical outcome only to the intrinsic features of the HPV-infected cells. It is more likely that a complex paracrine interaction among intrinsically mediated key pathways and the tumor microenvironment, including cells of the immune system, may determine the accelerated sensitivity to either radiation or chemotherapy (Figure 2). Accordingly, HPV-positive tumors have been postulated to be more susceptible to immune surveillance of tumorspecific antigens (Argiris et al., 2008), but so far only a few studies have explored endogenous host immunity to viral proteins in HNSCC patients, in order to elucidate pathogenetic and treatment-response mechanisms, and to gain insights into novel immunotherapeutic strategies.

Cytotoxic therapies including radiation induce potentially immunogenic cell death, releasing tumor-associated antigens, as a "danger" signal to the immune system (Shinohara and Maity, 2009). The efficacy of radiotherapy is determined not only by tumor cell properties, but also endothelial cells and infiltrating immune cells within the tumor environment (Shinohara and Maity, 2009). High levels of tumor-infiltrating lymphocytes (TILs) have been identified as a favorable prognostic biomarker in various cancers (Pages et al., 2010), including HNSCC (Brandwein-Gensler et al., 2005; Lopez-Albaitero et al., 2006; Uppaluri et al., 2008). However, their exact role on HNSCC, especially in the context of HPV-related tumors remains to be elucidated. In this context, Hoffmann et al. found that the frequency of HPV16-E7-specific T cells in the serum did not differ between HNSCC patients and healthy controls. However, higher frequencies of T cells specific for HPV16-E7 epitopes were observed in HNSCC patients with HPV-related tumors (Hoffmann et al., 2006), which is in line with previous findings (Albers et al., 2005). The fact that HPV16-E7 epitopes are apparently immunogenic raises the question as to why antigen-specific $\mathrm{T}$ cells in HNSCC patients are unable to eliminate HPV-related tumors without treatment. One possible explanation was provided by the finding that E7-specific cytotoxic T cells obtained by in vitro stimulation only recognize human leukocyte antigen HLA-A*201 positive and HPV16-transformed HNSCC cells after pretreatment with IFN-gamma (Albers et al., 2005). Further analysis demonstrated that this cell line had little or no expression of critical components of the HLA class I antigenprocessing machinery, which were subsequently up-regulated upon IFN-gamma treatment. In addition, the antigen-processing machinery components were also found to be downregulated in HPV-related tumors compared to adjacent normal epithelium. It currently remains uncertain as to whether impaired antigen presentation in HPV-related tumors may be reversed by radiation or chemotherapy and thereby induces an antitumor immune response.

In a retrospective study, Rajjoub et al. (2007) reported a positive correlation between large numbers of TILs (CD $3^{\text {high }}$ ) and lower incidence of metastasis at presentation, regardless of HPV status. However, when the HPV status was taken into account, the correlation between a $\mathrm{CD} 3^{\text {high }}$ count and a lower rate of metastasis was maintained in HPV-positive but not in HPV-negative patients (Rajjoub et al., 2007), further supporting the crucial role of the adaptive immunity in the favorable clinical outcome of HPVrelated tumors. In line with this assumption, the percentage of circulating CD8-positive T cells was significantly higher in patients with HPV-related tumors as compared to HPV-negative HNSCC patients (Wansom et al., 2010). Furthermore this prospective study revealed a positive correlation between a higher percentage of CD8-positive T cells and the response to induction chemotherapy and complete tumor response after chemotherapy. However in a subsequent study, Wansom et al. (2012) reported that the degree of $\mathrm{T}$ cell infiltration in tumor tissue is associated with improved survival but is independent of the HPV status, similar to previous findings (Rajjoub et al., 2007; Wansom et al., 2012). They concluded that more comprehensive studies with larger numbers of patients combined with functional analysis of individual subsets may be necessary to detect significant differences in local immunity in HPV-related HNSCC.

There is increasing evidence that radiotherapy modulates immune response and that the underlying mechanism behind the better prognosis of HPV-positive tumors may be enhanced immune response following radiotherapy (Vu et al., 2010). In a recent study, Spanos et al. (2009) found that both HPVpositive human and murine transformed cell lines cells were even more resistant to radiation and cisplatin treatment in vitro compared with HPV-negative counterparts. However, HPVpositive cells were more sensitive to radiation in a syngeneic 
mouse tumor model, and complete clearance was found at $20 \mathrm{~Gy}$, in contrast to HPV-negative cells, which showed persistent growth (Spanos et al., 2009). Similar data were also obtained upon cisplatin treatment. Intriguingly, neither radiation nor cisplatin therapy cured HPV-positive tumors in immune-incompetent mice, strongly supporting a crucial role of the immune system in the therapeutic sensitivity of HPVpositive tumors. In line with this assumption, Williams et al. (2009) showed in a syngeneic mouse tumor model that only HPV-positive tumor cells induce an antigen-specific antitumor response, which was mediated by CD4- and CD8-positive T lymphocytes.

Innate immune cells may also contribute to the favorable clinical outcome of patients with HPV-related OPSCCs. As basal keratinocytes are the primary target of HPV infection (Feller et al., 2009), innate immunity represents the first line of defense against invading viruses. Keratinocytes express several pathogen recognition receptors (PRRs; Pries et al., 2008), and their engagement by pathogen-associated or danger-associated molecular patterns leads to direct activation of the pro-inflammatory transcription factors, and/or activation of an anti-viral type I interferon (IFN) response (Rincon-Orozco et al., 2009; Muto et al., 2011). Several reports highlighted a major impact of viral oncoproteins on the regulation of pro-inflammatory mediators and anti-viral responses, suggesting that HPV has developed strategies to evade the innate host immunity (Schlecht et al., 2007; Jung et al., 2010; Karim et al., 2011). For example, expression of the pro-inflammatory molecules S100A8 and S100A9 were downregulated in HPV-immortalized cells (Dell'oste et al., 2008). Vice versa, the S100A8/S100A9 protein complex has been shown to inhibit phosphorylation of the viral E7 oncoprotein by the casein kinase II and may play an important role in HPV-infected epithelial cells to counteract the oncogenic activity of E7 (Tugizov et al., 2005). S100A8 (MRP8) and S100A9 (MRP14) belong to the large family of S100 proteins, which are low molecular weight proteins sharing conserved structural motifs that consist of two EF-hand $\mathrm{Ca}^{2+}$-binding domains. S100A8 and S100A9 form a functional heterodimer (also known as calprotectin) and have been identified as important endogenous damage-associated molecular pattern proteins that critically contribute to pathological conditions of acute and chronic inflammation, and may therefore represent a key player in the setting of inflammation-associated carcinogenesis (Gebhardt et al., 2006; Nemeth et al., 2009). It is worth mentioning, that inflammatory signals and the establishment of a pro-inflammatory environment are increasingly linked to the induction and promotion of tumorigenesis (Balkwill and Mantovani, 2001; Coussens and Werb, 2002; Grivennikov et al., 2010). One of the most extensively studied signaling network in inflammation-associated cancer is the NF- $\kappa \mathrm{B}$ pathway (Ben-Neriah and Karin, 2011), and there is increasing evidence

\section{REFERENCES}

Agrawal, N., Frederick, M. J., Pickering, C. R., Bettegowda, C., Chang, K., Li, R. J., Fakhry, C., Xie, T. X., Zhang, J., Wang, J., Zhang, N., El-Naggar, A. K., Jasser, S. A., Weinstein, J. N., Trevino, L., Drummond, J. A., Muzny, D. M.,

for its crucial role in the pathogenesis of HNSCC including HPV-related tumors (Molinolo et al., 2009). Analysis of HPV16transformed cell lines revealed that functional components of the NF- $\kappa \mathrm{B}$ signaling pathway were sequestered in the cytoplasm, or became inactivated by viral E6 and E7 expression, accompanied by reduced expression of cytokines and chemokines (Guess and McCance, 2005; Havard et al., 2005). However, it will be a challenge for the future to address the question of whether changes in pro-inflammatory signaling pathways, such as NF- $\kappa$, and the establishment of an activated pro-tumorigenic environment are causally linked to the increased sensitivity to therapy of patients with HPV-related tumors and their improved survival.

\section{CONCLUSION AND PERSPECTIVES}

Currently, HPV-positive OPSCC dominates the head and neck oncology landscape, and its escalating incidence has a strong impact on clinical and translational research. Although it is well accepted that HPV-related tumors represent a distinct histopathological and biological entity with a favorable clinical outcome, we have just now begun to establish the molecular principles underlying improved survival. As a consequence of modern genome-wide approaches, our understanding of the fundamental mechanisms and biological processes involved in the pathogenesis of HPV-related and HPV-negative HNSCCs has rapidly increased. However, most of the functional genomics data was derived from primary tumor samples largely devoid of the important information on differences in response to current treatment options. Furthermore, the use of several cell culture and mouse tumor models have produced conflicting results which neither mimic the complex interaction between the tumor and its activated tumor microenvironment nor the etiology of HPV-related tumors. Hence, there is an urgent need for an appropriate and more sophisticated preclinical model $\operatorname{system}(\mathrm{s})$.

The mechanisms underlying the clinical differences between HPV-related and HPV-negative tumors may involve the combined effects of tumor cell intrinsic features and paracrine interactions between tumor cells and stromal cells of the activated tumor microenvironment, especially cells of the adaptive and innate immunity. Unraveling the molecular nature of improved clinical outcome of HPV-related HNSCC will not only support personalized risk assessment but will also unravel new concepts for a targeted therapy for HNSCC patients with HPV-negative tumors.

\section{ACKNOWLEDGMENTS}

Our research program is supported by the Dietmar Hopp Foundation and the Foundation Tumorforschung Kopf-Hals. We gratefully acknowledge Thomas Fleming's help in preparing the manuscript.

head and neck squamous cell carcinoma reveals inactivating mutations in NOTCH1. Science 333, 1154-1157.

Albers, A., Abe, K., Hunt, J., Wang, J., Lopez-Albaitero, A., Schaefer, C., Gooding, W., Whiteside, T. L.,
Ferrone, S., Deleo, A., and Ferris, R. L. (2005). Antitumor activity of human papillomavirus type 16 E7-specific $T$ cells against virally infected squamous cell carcinoma of the head and neck. Cancer Res. 65, 11146-11155. 
Andl, T., Kahn, T., Pfuhl, A., Nicola, T., Erber, R., Conradt, C., Klein, W., Helbig, M., Dietz, A., Weidauer, H., and Bosch, F. X. (1998). Etiological involvement of oncogenic human papillomavirus in tonsillar squamous cell carcinomas lacking retinoblastoma cell cycle control. Cancer Res. 58, 5-13.

Ang, K. K., Harris, J., Wheeler, R., Weber, R., Rosenthal, D. I., Nguyen-Tan, P. F., Westra, W. H., Chung, C. H., Jordan, R. C., Lu, C., Kim, H., Axelrod, R., Silverman, C. C., Redmond, K. P., and Gillison, M. L. (2010). Human papillomavirus and survival of patients with oropharyngeal cancer. N. Engl. J. Med. 363, 24-35.

Argiris, A., Karamouzis, M. V., Raben, D., and Ferris, R. L. (2008). Head and neck cancer. Lancet 371, 1695-1709.

Attner, P., Du, J., Nasman, A., Hammarstedt, L., Ramqvist, T., Lindholm, J., Marklund, L., Dalianis, T., and Munck-Wikland, E. (2010). The role of human papillomavirus in the increased incidence of base of tongue cancer. Int. J. Cancer 126, 2879-2884.

Babu, J. M., Prathibha, R., Jijith, V. S., Hariharan, R., and Pillai, M. R. (2011). A miR-centric view of head and neck cancers. Biochim. Biophys. Acta 1816, 67-72.

Balkwill, F., and Mantovani, A. (2001). Inflammation and cancer: back to Virchow? Lancet 357, 539-545.

Begum, S., Cao, D., Gillison, M., Zahurak, M., and Westra, W. H. (2005). Tissue distribution of human papillomavirus 16 DNA integration in patients with tonsillar carcinoma. Clin. Cancer Res. 11, 5694-5699.

Ben-Neriah, Y., and Karin, M. (2011). Inflammation meets cancer, with NF-kappaB as the matchmaker. Nat. Immunol. 12, 715-723.

Braakhuis, B. J., Snijders, P. J., Keune, W. J., Meijer, C. J., Ruijter-Schippers, H. J., Leemans, C. R., and Brakenhoff, R. H. (2004). Genetic patterns in head and neck cancers that contain or lack transcriptionally active human papillomavirus. J. Natl. Cancer Inst. 96, 998-1006.

Brandwein-Gensler, M., Teixeira, M. S., Lewis, C. M., Lee, B., Rolnitzky, L., Hille, J. J., Genden, E., Urken, M. L., and Wang, B. Y. (2005). Oral squamous cell carcinoma: histologic risk assessment, but not margin status, is strongly predictive of local diseasefree and overall survival. Am. J. Surg. Pathol. 29, 167-178.

Brumbaugh, K. M., Otterness, D. M., Geisen, C., Oliveira, V., Brognard, J., Li, X., Lejeune, F., Tibbetts, R.
S., Maquat, L. E., and Abraham, R. T. (2004). The mRNA surveillance protein hSMG-1 functions in genotoxic stress response pathways in mammalian cells. Mol. Cell 14, 585-598.

Carvalho, A. L., Jeronimo, C., Kim, M. M., Henrique, R., Zhang, Z., Hoque, M. O., Chang, S., Brait, M., Nayak, C. S., Jiang, W. W., Claybourne, Q., Tokumaru, Y., Lee, J., Goldenberg, D., Garrett-Mayer, E., Goodman, S., Moon, C. S., Koch, W., Westra, W. H., Sidransky, D., and Califano, J. A. (2008). Evaluation of promoter hypermethylation detection in body fluids as a screening/diagnosis tool for head and neck squamous cell carcinoma. Clin. Cancer Res. 14, 97-107.

Coussens, L. M., and Werb, Z. (2002). Inflammation and cancer. Nature $420,860-867$.

Curado, M. P., and Hashibe, M. (2009). Recent changes in the epidemiology of head and neck cancer. Curr. Opin. Oncol. 21, 194-200.

Dahlgren, L., Mellin, H., Wangsa, D., Heselmeyer-Haddad, K., Bjornestal, L., Lindholm, J., Munck-Wikland, E., Auer, G., Ried, T., and Dalianis, T. (2003). Comparative genomic hybridization analysis of tonsillar cancer reveals a different pattern of genomic imbalances in human papillomavirus-positive and -negative tumors. Int. J. Cancer 107, 244-249.

Dell'oste, V., Azzimonti, B., Mondini, M., De Andrea, M., Borgogna, C., Mesturini, R., Accardi, R., Tommasino, M., Landolfo, S., Dianzani, U., and Gariglio, M. (2008). Altered expression of UVB-induced cytokines in human papillomavirusimmortalized epithelial cells. J. Gen. Virol. 89, 2461-2466.

Dikshit, R. P., Gillio-Tos, A., Brennan, P., De Marco, L., Fiano, V., MartinezPenuela, J. M., Boffetta, P., and Merletti, F. (2007). Hypermethylation, risk factors, clinical characteristics, and survival in 235 patients with laryngeal and hypopharyngeal cancers. Cancer 110, 1745-1751.

Dong, S. M., Sun, D. I., Benoit, N. E., Kuzmin, I., Lerman, M. I., and Sidransky, D. (2003). Epigenetic inactivation of RASSF1A in head and neck cancer. Clin. Cancer Res. 9, 3635-3640.

D’Souza, G., Kreimer, A. R., Viscidi, R., Pawlita, M., Fakhry, C., Koch, W. M., Westra, W. H., and Gillison, M. L. (2007). Case-control study of human papillomavirus and oropharyngeal cancer. N. Engl. J. Med. 356, 1944-1956.
El-Naggar, A. K., Lai, S., Clayman, G., Lee, J. K., Luna, M. A., Goepfert, H., and Batsakis, J. G. (1997). Methylation, a major mechanism of p16/CDKN2 gene inactivation in head and neck squamous carcinoma. Am. J. Pathol. 151, 1767-1774.

Ernster, J. A., Sciotto, C. G., O’brien, M. M., Finch, J. L., Robinson, L. J., Willson, T., and Mathews, M. (2007). Rising incidence of oropharyngeal cancer and the role of oncogenic human papilloma virus. Laryngoscope 117, 2115-2128.

Fakhry, C., Westra, W. H., Li, S., Cmelak, A., Ridge, J. A., Pinto, H., Forastiere, A., and Gillison, M. L. (2008). Improved survival of patients with human papillomavirus-positive head and neck squamous cell carcinoma in a prospective clinical trial. J. Natl. Cancer Inst. 100, 261-269.

Feller, L., Khammissa, R. A., Wood, N. H., and Lemmer, J. (2009). Epithelial maturation and molecular biology of oral HPV. Infect. Agents Cancer 4, 16.

Furniss, C. S., Mcclean, M. D., Smith, J. F., Bryan, J., Applebaum, K. M., Nelson, H. H., Posner, M. R., and Kelsey, K. T. (2009). Human papillomavirus 6 seropositivity is associated with risk of head and neck squamous cell carcinoma, independent of tobacco and alcohol use. Ann. Oncol. 20, 534-541.

Gebhardt, C., Nemeth, J., Angel, P., and Hess, J. (2006). S100A8 and S100A9 in inflammation and cancer. Biochem. Pharmacol. 72, 1622-1631.

Gewandter, J. S., Bambara, R. A., and O'reilly, M. A. (2011). The RNA surveillance protein SMG1 activates p53 in response to DNA double-strand breaks but not exogenously oxidized mRNA. Cell Cycle 10, 2561-2567.

Gillison, M. L., D’Souza, G., Westra, W., Sugar, E., Xiao, W., Begum, S., and Viscidi, R. (2008). Distinct risk factor profiles for human papillomavirus type 16-positive and human papillomavirus type 16negative head and neck cancers. $J$. Natl. Cancer Inst. 100, 407-420.

Gillison, M. L., Koch, W. M., Capone, R. B., Spafford, M., Westra, W. H., Wu, L., Zahurak, M. L., Daniel, R. W., Viglione, M., Symer, D. E., Shah, K. V., and Sidransky, D. (2000). Evidence for a causal association between human papillomavirus and a subset of head and neck cancers. J. Natl. Cancer Inst. 92, 709-720.

Grivennikov, S. I., Greten, F. R., and Karin, M. (2010). Immunity, inflammation, and cancer. Cell 140, 883-899.
Gubanova, E., Brown, B. T., Ivanov, S. V., Helleday, T., Mills, G. B., Yarbrough, W. G., and Issaeva, N. (2012). Downregulation of SMG1 in HPV-positive head and neck squamous cell carcinoma due to promoter hypermethylation correlates with improved survival. Clin. Cancer Res. 18, 1257-1267.

Guess, J. C., and McCance, D. J. (2005). Decreased migration of Langerhans precursor-like cells in response to human keratinocytes expressing human papillomavirus type $16 \mathrm{E} 6 / \mathrm{E} 7$ is related to reduced macrophage inflammatory protein3alpha production. J. Virol. 79, 14852-14862.

Haddad, R. I., and Shin, D. M. (2008). Recent advances in head and neck cancer. N. Engl. J. Med. 359, 1143-1154.

Hampson, L., El Hady, E. S., Moore, J. V., Kitchener, H., and Hampson, I. N. (2001). The HPV16 E6 and E7 proteins and the radiation resistance of cervical carcinoma. FASEB J. 15, 1445-1447.

Hanahan, D., and Weinberg, R. A (2000). The hallmarks of cancer. Cell 100, 57-70.

Hanahan, D., and Weinberg, R. A. (2011). Hallmarks of cancer: the next generation. Cell 144, 646-674.

Hasegawa, M., Nelson, H. H., Peters, E., Ringstrom, E., Posner, M., and Kelsey, K. T. (2002). Patterns of gene promoter methylation in squamous cell cancer of the head and neck. Oncogene 21, 4231-4236.

Havard, L., Rahmouni, S., Boniver, J., and Delvenne, P. (2005). High levels of p105 (NFKB1) and p100 (NFKB2) proteins in HPV16transformed keratinocytes: role of E6 and E7 oncoproteins. Virology 331, 357-366.

Hennessey, P. T., Ochs, M. F., Mydlarz, W. W., Hsueh, W., Cope, L., Yu, W., and Califano, J. A. (2011). Promoter methylation in head and neck squamous cell carcinoma cell lines is significantly different than methylation in primary tumors and xenografts. PLoS ONE 6, e20584. doi:10.1371/journal.pone.0020584

Hoffmann, M., Ihloff, A. S., Gorogh, T., Weise, J. B., Fazel, A., Krams, M. Rittgen, W., Schwarz, E., and Kahn, T. (2010). p16(INK4a) overexpression predicts translational active human papillomavirus infection in tonsillar cancer. Int. J. Cancer 127, 1595-1602.

Hoffmann, T. K., Arsov, C., Schirlau, K., Bas, M., Friebe-Hoffmann, U., Klussmann, J. P., Scheckenbach, K., Balz, V., Bier, H., and Whiteside, T. L. 
(2006). T cells specific for HPV16 E7 epitopes in patients with squamous cell carcinoma of the oropharynx. Int. J. Cancer 118, 1984-1991.

Hoffmann, T. K., Sonkoly, E., Hauser, U., Van Lierop, A., Whiteside, T. L., Klussmann, J. P., Hafner, D., Schuler, P., Friebe-Hoffmann, U., Scheckenbach, K., Erjala, K., Grenman, R., Schipper, J., Bier, H., and Balz, V. (2008). Alterations in the p53 pathway and their association with radioand chemosensitivity in head and neck squamous cell carcinoma. Oral Oncol. 44, 1100-1109.

Hunter, K. D., Parkinson, E. K., and Harrison, P. R. (2005). Profiling early head and neck cancer. Nat. Rev. Cancer 5, 127-135.

James, M. A., Lee, J. H., and Klingelhutz, A. J. (2006). Human papillomavirus type 16 E6 activates NF-kappaB, induces cIAP-2 expression, and protects against apoptosis in a PDZ binding motif-dependent manner. $J$. Virol. 80, 5301-5307.

Jung, A. C., Briolat, J., Millon, R., De Reynies, A., Rickman, D., Thomas, E., Abecassis, J., Clavel, C., and Wasylyk, B. (2010). Biological and clinical relevance of transcriptionally active human papillomavirus (HPV) infection in oropharynx squamous cell carcinoma. Int. J. Cancer 126, 1882-1894.

Karim, R., Meyers, C., Backendorf, C., Ludigs, K., Offringa, R., Van Ommen, G. J., Melief, C. J., Van Der Burg, S. H., and Boer, J. M. (2011). Human papillomavirus deregulates the response of a cellular network comprising of chemotactic and proinflammatory genes. PLoS ONE 6, e17848. doi:10.1371/journal.pone. 0017848

Kim, S. H., Koo, B. S., Kang, S., Park, K., Kim, H., Lee, K. R., Lee, M. J., Kim, J. M., Choi, E. C., and Cho, N. H. (2007). HPV integration begins in the tonsillar crypt and leads to the alteration of p16, EGFR and cmyc during tumor formation. Int. J. Cancer 120, 1418-1425.

Klussmann, J. P., Mooren, J. J., Lehnen, M., Claessen, S. M., Stenner, M., Huebbers, C. U., Weissenborn, S. J., Wedemeyer, I., Preuss, S. F., Straetmans, J. M., Manni, J. J., Hopman, A. H., and Speel, E. J. (2009). Genetic signatures of HPVrelated and unrelated oropharyngeal carcinoma and their prognostic implications. Clin. Cancer Res. 15, 1779-1786.

Klussmann, J. P., Weissenborn, S. J., Wieland, U., Dries, V., Kolligs, J., Jungehuelsing, M., Eckel, H. E., Dienes, H. P., Pfister, H. J., and
Fuchs, P. G. (2001). Prevalence, distribution, and viral load of human papillomavirus 16 DNA in tonsillar carcinomas. Cancer 92, 2875-2884.

Kreimer, A. R., Clifford, G. M., Snijders, P. J., Castellsague, X., Meijer, C. J., Pawlita, M., Viscidi, R., Herrero, R., and Franceschi, S. (2005). HPV16 semiquantitative viral load and serologic biomarkers in oral and oropharyngeal squamous cell carcinomas. Int. J. Cancer 115, 329-332.

Lajer, C. B., Nielsen, F. C., Friis-Hansen, L., Norrild, B., Borup, R., Garnaes, E., Rossing, M., Specht, L., Therkildsen, M. H., Nauntofte, B., Dabelsteen, S., and Von Buchwald, C. (2011). Different miRNA signatures of oral and pharyngeal squamous cell carcinomas: a prospective translational study. Br. J. Cancer 104, 830-840.

Leemans, C. R., Braakhuis, B. J., and Brakenhoff, R. H. (2011). The molecular biology of head and neck cancer. Nat. Rev. Cancer 11, 9-22.

Licitra, L., Perrone, F., Bossi, P., Suardi, S., Mariani, L., Artusi, R., Oggionni, M., Rossini, C., Cantu, G., Squadrelli, M., Quattrone, P., Locati, L. D., Bergamini, C., Olmi, P., Pierotti, M. A., and Pilotti, S. (2006). Highrisk human papillomavirus affects prognosis in patients with surgically treated oropharyngeal squamous cell carcinoma. J. Clin. Oncol. 24, 5630-5636.

Lindquist, D., Romanitan, M., Hammarstedt, L., Nasman, A., Dahlstrand, H., Lindholm, J., Onelov, L., Ramqvist, T., Ye, W., Munck-Wikland, E., and Dalianis, T. (2007). Human papillomavirus is a favourable prognostic factor in tonsillar cancer and its oncogenic role is supported by the expression of E6 and E7. Mol Oncol 1, 350-355.

Lohavanichbutr, P., Houck, J., Fan, W., Yueh, B., Mendez, E., Futran, N., Doody, D. R., Upton, M. P., Farwell, D. G., Schwartz, S. M., Zhao, L. P., and Chen, C. (2009). Genomewide gene expression profiles of HPVpositive and HPV-negative oropharyngeal cancer: potential implications for treatment choices. Arch. Otolaryngol. Head Neck Surg. 135, 180-188.

Lopez-Albaitero, A., Nayak, J. V., Ogino, T., Machandia, A., Gooding, W., Deleo, A. B., Ferrone, S., and Ferris, R. L. (2006). Role of antigenprocessing machinery in the in vitro resistance of squamous cell carcinoma of the head and neck cells to recognition by CTL. J. Immunol. 176, 3402-3409.

Mansour, A., Ali, M., Helmy, H., and Kassim, S. (2012). Human papillomavirus-16 (HPV-16) infection association with CIAP-2 expression in head and neck cancer. Med. Oncol. doi: 10.1007/s12032011-0143-2. [Epub ahead of print].

Marsit, C. J., Christensen, B. C., Houseman, E. A., Karagas, M. R., Wrensch, M. R., Yeh, R. F., Nelson, H. H., Wiemels, J. L., Zheng, S., Posner, M. R., Mcclean, M. D., Wiencke, J. K., and Kelsey, K. T. (2009). Epigenetic profiling reveals etiologically distinct patterns of DNA methylation in head and neck squamous cell carcinoma. Carcinogenesis 30, 416-422.

Marsit, C. J., Mcclean, M. D., Furniss, C. S., and Kelsey, K. T. (2006). Epigenetic inactivation of the SFRP genes is associated with drinking, smoking and HPV in head and neck squamous cell carcinoma. Int. J. Cancer 119, 1761-1766.

Marsit, C. J., Posner, M. R., Mcclean, M. D., and Kelsey, K. T. (2008). Hypermethylation of E-cadherin is an independent predictor of improved survival in head and neck squamous cell carcinoma. Cancer 113, 1566-1571.

Martinez, I., Wang, J., Hobson, K. F., Ferris, R. L., and Khan, S. A. (2007). Identification of differentially expressed genes in HPVpositive and HPV-negative oropharyngeal squamous cell carcinomas. Eur. J. Cancer 43, 415-432.

Martone, T., Gillio-Tos, A., De Marco, L., Fiano, V., Maule, M., Cavalot, A., Garzaro, M., Merletti, F., and Cortesina, G. (2007). Association between hypermethylated tumor and paired surgical margins in head and neck squamous cell carcinomas. Clin. Cancer Res. 13, 5089-5094.

Marur, S., D'Souza, G., Westra, W. H., and Forastiere, A. A. (2010). HPV-associated head and neck cancer: a virus-related cancer epidemic. Lancet Oncol. 11, 781-789.

Masuda, M., Wakasaki, T., Toh, S., Shimizu, M., and Adachi, S. (2011). Chemoprevention of head and neck cancer by green tea extract: EGCGthe role of EGFR signaling and "lipid raft.” J. Oncol. 2011, 540148.

Mellin, H., Dahlgren, L., MunckWikland, E., Lindholm, J., Rabbani, H., Kalantari, M., and Dalianis, T. (2002). Human papillomavirus type 16 is episomal and a high viral load may be correlated to better prognosis in tonsillar cancer. Int. J. Cancer 102, 152-158.

Molinolo, A. A., Amornphimoltham, P., Squarize, C. H., Castilho, R. M., Patel, V., and Gutkind, J. S. (2009).
Dysregulated molecular networks in head and neck carcinogenesis. Oral Oncol. 45, 324-334.

Munoz-Antonia, T., Torrellas-Ruiz, M., Clavell, J., Mathews, L. A., MuroCacho, C. A., and Baez, A. (2009). Aberrant methylation inactivates transforming growth factor beta receptor I in head and neck squamous cell carcinoma. Int. J. Otolaryngol. 2009, 848695.

Muto, V., Stellacci, E., Lamberti, A. G., Perrotti, E., Carrabba, A., Matera, G., Sgarbanti, M., Battistini, A., Liberto, M. C., and Foca, A. (2011). Human papillomavirus type 16 E5 protein induces expression of beta interferon through interferon regulatory factor 1 in human keratinocytes. J. Virol. 85, 5070-5080.

Nagata, M., Nakayama, H., Tanaka, T., Yoshida, R., Yoshitake, Y., Fukuma, D., Kawahara, K., Nakagawa, Y., Ota, K., Hiraki, A., and Shinohara, M. (2011). Overexpression of cIAP2 contributes to 5-FU resistance and a poor prognosis in oral squamous cell carcinoma. Br. J. Cancer 105, 1322-1330.

Nemeth, J., Stein, I., Haag, D., Riehl, A., Longerich, T., Horwitz, E. Breuhahn, K., Gebhardt, C., Schirmacher, P., Hahn, M., Ben-Neriah, Y., Pikarsky, E., Angel, P., and Hess, J. (2009). S100A8 and S100A9 are novel nuclear factor kappa B target genes during malignant progression of murine and human liver carcinogenesis. Hepatology 50, 1251-1262.

Padilla, L. A., Leung, B. S., and Carson, L. F. (2002). Evidence of an association between human papillomavirus and impaired chemotherapy-induced apoptosis in cervical cancer cells. Gynecol. Oncol. 85, 59-66.

Pages, F., Galon, J., Dieu-Nosjean, M. C., Tartour, E., Sautes-Fridman, C., and Fridman, W. H. (2010). Immune infiltration in human tumors: a prognostic factor that should not be ignored. Oncogene 29, 1093-1102.

Pai, S. I., and Westra, W. H. (2009). Molecular pathology of head and neck cancer: implications for diagnosis, prognosis, and treatment. Annu. Rev. Pathol. 4, 49-70.

Pang, E., Delic, N. C., Hong, A. Zhang, M., Rose, B. R., and Lyons, J. G. (2011). Radiosensitization of oropharyngeal squamous cell carcinoma cells by human papillomavirus 16 oncoprotein E6 $*$ I. Int J. Radiat. Oncol. Biol. Phys. 79, 860-865.

Paz, I. B., Cook, N., Odom-Maryon, T., Xie, Y., and Wilczynski, S. P. (1997). Human papillomavirus (HPV) in 
head and neck cancer. An association of HPV 16 with squamous cell carcinoma of Waldeyer's tonsillar ring. Cancer 79, 595-604.

Preuss, S. F., Weinell, A., Molitor, M., Stenner, M., Semrau, R., Drebber, U., Weissenborn, S. J., Speel, E. J., Wittekindt, C., Guntinas-Lichius, O., Hoffmann, T. K., Eslick, G. D., and Klussmann, J. P. (2008). Nuclear survivin expression is associated with HPV-independent carcinogenesis and is an indicator of poor prognosis in oropharyngeal cancer. Br. J. Cancer 98, 627-632.

Pries, R., Wulff, S., and Wollenberg, B. (2008). Toll-like receptor modulation in head and neck cancer. Crit. Rev. Immunol. 28, 201-213.

Psyrri, A., and Dimaio, D. (2008). Human papillomavirus in cervical and head-and-neck cancer. Nat. Clin. Pract. Oncol. 5, 24-31.

Puri, S. K., Si, L., Fan, C. Y., and Hanna, E. (2005). Aberrant promoter hypermethylation of multiple genes in head and neck squamous cell carcinoma. Am. J. Otolaryngol. 26, 12-17.

Pyeon, D., Newton, M. A., Lambert, P. F., Den Boon, J. A., Sengupta, S., Marsit, C. J., Woodworth, C. D., Connor, J. P., Haugen, T. H., Smith, E. M., Kelsey, K. T., Turek, L. P., and Ahlquist, P. (2007). Fundamental differences in cell cycle deregulation in human papillomavirus-positive and human papillomavirus-negative head/neck and cervical cancers. Cancer Res. 67, 4605-4619.

Qi, G., Kudo, Y., Ando, T., Tsunematsu, T., Shimizu, N., Siriwardena, S. B., Yoshida, M., Keikhaee, M. R., Ogawa, I., and Takata, T. (2010). Nuclear survivin expression is correlated with malignant behaviors of head and neck cancer together with Aurora-B. Oral Oncol. 46, 263-270.

Rajjoub, S., Basha, S. R., Einhorn, E., Cohen, M. C., Marvel, D. M., and Sewell, D. A. (2007). Prognostic significance of tumor-infiltrating lymphocytes in oropharyngeal cancer. Ear Nose Throat J. 86, 506-511.

Reimers, N., Kasper, H. U., Weissenborn, S. J., Stutzer, H., Preuss, S. F., Hoffmann, T. K., Speel, E. J., Dienes, H. P., Pfister, H. J., Guntinas-Lichius, O., and Klussmann, J. P. (2007). Combined analysis of HPV-DNA, p16 and EGFR expression to predict prognosis in oropharyngeal cancer. Int. J. Cancer 120, 1731-1738.

Richards, K. L., Zhang, B., Baggerly, K. A., Colella, S., Lang, J. C., Schuller, D. E., and Krahe, R. (2009). Genomewide hypomethylation in head and neck cancer is more pronounced in
HPV-negative tumors and is associated with genomic instability. PLoS ONE 4, e4941. doi:10.1371/journal.pone.0004941

Righini, C. A., De Fraipont, F., Timsit, J. F., Faure, C., Brambilla, E., Reyt, E., and Favrot, M. C. (2007). Tumor-specific methylation in saliva: a promising biomarker for early detection of head and neck cancer recurrence. Clin. Cancer Res. 13, 1179-1185.

Rincon-Orozco, B., Halec, G., Rosenberger, S., Muschik, D., Nindl, I., Bachmann, A., Ritter, T. M., Dondog, B., Ly, R., Bosch, F. X. Zawatzky, R., and Rosl, F. (2009). Epigenetic silencing of interferonkappa in human papillomavirus type 16-positive cells. Cancer Res. 69, 8718-8725.

Rodriguez, C. S., Mcmillan, S., and Yarandi, H. (2004). Pain measurement in older adults with head and neck cancer and communication impairments. Cancer Nurs. 27, 425-433.

Sartor, M. A., Dolinoy, D. C., Jones, T. R., Colacino, J. A., Prince, M. E., Carey, T. E., and Rozek, L. S. (2011). Genome-wide methylation and expression differences in HPV(+) and HPV(-) squamous cell carcinoma cell lines are consistent with divergent mechanisms of carcinogenesis. Epigenetics 6, 777-787.

Schlecht, N. F., Burk, R. D., Adrien, L., Dunne, A., Kawachi, N., Sarta, C., Chen, Q., Brandwein-Gensler, M., Prystowsky, M. B., Childs, G., Smith, R. V., and Belbin, T. J. (2007). Gene expression profiles in HPV-infected head and neck cancer. J. Pathol. 213, 283-293.

Schmezer, P., and Plass, C. (2008). Epigenetic aspects in carcinomas of the head and neck. HNO 56, 594-602.

Sheu, J. J., Hua, C. H., Wan, L., Lin, Y. J., Lai, M. T., Tseng, H. C., Jinawath, N., Tsai, M. H., Chang, N. W., Lin, C. F., Lin, C. C., Hsieh, L. J., Wang, T. L., Shih Ie, M., and Tsai, F. J. (2009). Functional genomic analysis identified epidermal growth factor receptor activation as the most common genetic event in oral squamous cell carcinoma. Cancer Res. 69, 2568-2576.

Shiloh, Y. (2003). ATM and related protein kinases: safeguarding genome integrity. Nat. Rev. Cancer 3, 155-168.

Shinohara, E. T., and Maity, A. (2009). Increasing sensitivity to radiotherapy and chemotherapy by using novel biological agents that alter the tumor microenvironment. Curr. Mol. Med. 9, 1034-1045.
Slebos, R. J., Yi, Y., Ely, K., Carter, J., Evjen, A., Zhang, X., Shyr, Y., Murphy, B. M., Cmelak, A. J., Burkey, B. B., Netterville, J. L., Levy, S., Yarbrough, W. G., and Chung, C. H. (2006). Gene expression differences associated with human papillomavirus status in head and neck squamous cell carcinoma. Clin. Cancer Res. 12, 701-709.

Smeets, S. J., Braakhuis, B. J., Abbas, S., Snijders, P. J., Ylstra, B., Van De Wiel, M. A., Meijer, G. A. Leemans, C. R., and Brakenhoff, R. H. (2006). Genome-wide DNA copy number alterations in head and neck squamous cell carcinomas with or without oncogeneexpressing human papillomavirus. Oncogene 25, 2558-2564.

Spanos, W. C., Nowicki, P., Lee, D. W., Hoover, A., Hostager, B., Gupta, A., Anderson, M. E., and Lee, J. H. (2009). Immune response during therapy with cisplatin or radiation for human papillomavirusrelated head and neck cancer. Arch. Otolaryngol. Head Neck Surg. 135 1137-1146.

Stauber, R. H., Mann, W., and Knauer, S. K. (2007). Nuclear and cytoplasmic survivin: molecular mechanism, prognostic, and therapeutic potential. Cancer Res. 67, 5999-6002.

Stransky, N., Egloff, A. M., Tward, A. D., Kostic, A. D., Cibulskis, K., Sivachenko, A., Kryukov, G. V., Lawrence, M. S., Sougnez, C., Mckenna, A., Shefler, E., Ramos, A H., Stojanov, P., Carter, S. L., Voet, D., Cortes, M. L., Auclair, D., Berger, M. F., Saksena, G., Guiducci, C. Onofrio, R. C., Parkin, M., Romkes, M., Weissfeld, J. L., Seethala, R. R., Wang, L., Rangel-Escareno, C. Fernandez-Lopez, J. C., HidalgoMiranda, A., Melendez-Zajgla, J., Winckler, W., Ardlie, K., Gabriel, S. B., Meyerson, M., Lander, E. S., Getz G., Golub, T. R., Garraway, L. A., and Grandis, J. R. (2011). The mutational landscape of head and neck squamous cell carcinoma. Science 333, 1157-1160.

Taioli, E., Ragin, C., Wang, X. H., Chen, J., Langevin, S. M., Brown, A. R., Gollin, S. M., Garte, S., and Sobol, R. W. (2009). Recurrence in oral and pharyngeal cancer is associated with quantitative MGMT promoter methylation. BMC Cancer 9, 354. doi:10.1186/1471-2407-9-354

Temam, S., Kawaguchi, H., El-Naggar, A. K., Jelinek, J., Tang, H., Liu, D. D., Lang, W., Issa, J. P., Lee, J. J., and Mao, L. (2007). Epidermal growth factor receptor copy number alterations correlate with poor clinical outcome in patients with head and neck squamous cancer. J. Clin. Oncol. 25, 2164-2170.

Tugizov, S., Berline, J., Herrera, R., Penaranda, M. E., Nakagawa, M. and Palefsky, J. (2005). Inhibition of human papillomavirus type $16 \mathrm{E} 7$ phosphorylation by the S100 MRP8/14 protein complex. J. Virol. 79, 1099-1112.

Uppaluri, R., Dunn, G. P., and Lewis, J. S. Jr. (2008). Focus on TILs: prognostic significance of tumor infiltrating lymphocytes in head and neck cancers. Cancer Immun. 8, 16.

van Houten, V. M., Snijders, P. J., Van Den Brekel, M. W., Kummer, J. A., Meijer, C. J., Van Leeuwen, B., Denkers, F., Smeele, L. E., Snow, G. B., and Brakenhoff, R. H. (2001). Biological evidence that human papillomaviruses are etiologically involved in a subgroup of head and neck squamous cell carcinomas. Int. J. Cancer 93, 232-235.

Vu, H. L., Sikora, A. G., Fu, S., and Kao, J. (2010). HPV-induced oropharyngeal cancer, immune response and response to therapy. Cancer Lett. 288, 149-155.

Wald, A. I., Hoskins, E. E., Wells, S. I., Ferris, R. L., and Khan, S. A. (2011). Alteration of microRNA profiles in squamous cell carcinoma of the head and neck cell lines by human papillomavirus. Head Neck 33, 504-512.

Wansom, D., Light, E., Thomas, D., Worden, F., Prince, M., Urba, S., Chepeha, D., Kumar, B., Cordell, K., Eisbruch, A., Taylor, J., Moyer, J., Bradford, C., D’Silva, N., Carey, T., Mchugh, J., and Wolf, G. (2012). Infiltrating lymphocytes and human papillomavirus-16 - associated oropharyngeal cancer. Laryngoscope 122, 121-127.

Wansom, D., Light, E., Worden, F., Prince, M., Urba, S., Chepeha, D. B., Cordell, K., Eisbruch, A., Taylor, J., D'Silva, N., Moyer, J., Bradford, C. R., Kurnit, D., Kumar, B., Carey, T. E., and Wolf, G. T. (2010). Correlation of cellular immunity with human papillomavirus 16 status and outcome in patients with advanced oropharyngeal cancer. Arch. Otolaryngol. Head Neck Surg. 136, 1267-1273.

Weber, A., Hengge, U. R., Bardenheuer, W., Tischoff, I., Sommerer, F., Markwarth, A., Dietz, A., Wittekind, C., and Tannapfel, A. (2005). SOCS-3 is frequently methylated in head and neck squamous cell carcinoma and its precursor lesions and causes growth inhibition. Oncogene 24, 6699-6708. 
Weiss, D., Basel, T., Sachse, F., Braeuninger, A., and Rudack, C. (2011). Promoter methylation of cyclin Al is associated with human papillomavirus 16 induced head and neck squamous cell carcinoma independently of p53 mutation. Mol. Carcinog. 50, 680-688.

Westra, W. H., Taube, J. M., Poeta, M. L., Begum, S., Sidransky, D., and Koch, W. M. (2008). Inverse relationship between human papillomavirus-16 infection and disruptive p53 gene mutations in squamous cell carcinoma of the head and neck. Clin. Cancer Res. 14, 366-369.

Wiest, T., Schwarz, E., Enders, C., Flechtenmacher, C., and Bosch, F. X. (2002). Involvement of intact HPV16 E6/E7 gene expression in head and neck cancers with unaltered p53 status and perturbed pRb cell cycle control. Oncogene 21, 1510-1517.
Williams, R., Lee, D. W., Elzey, B. D., Anderson, M. E., Hostager, B. S., and Lee, J. H. (2009). Preclinical models of HPV+ and HPV- HNSCC in mice: an immune clearance of HPV+ HNSCC. Head Neck 31, 911-918.

Wilting, S. M., Smeets, S. J., Snijders, P. J., Van Wieringen, W. N., Van De Wiel, M. A., Meijer, G. A., Ylstra, B., Leemans, C. R., Meijer, C. J., Brakenhoff, R. H., Braakhuis, B. J., and Steenbergen, R. D. (2009). Genomic profiling identifies common HPV-associated chromosomal alterations in squamous cell carcinomas of cervix and head and neck. BMC Med. Genomics 2, 32. doi:10.1186/1755-8794-2-32

Wong, T. S., Man, M. W., Lam, A. K., Wei, W. I., Kwong, Y. L., and Yuen, A. P. (2003). The study of p16 and p15 gene methylation in head and neck squamous cell carcinoma and their quantitative evaluation in plasma by real-time PCR. Eur. J. Cancer 39, 1881-1887.
Wu, H. H., Wu, J. Y., Cheng, Y. W., Chen, C. Y., Lee, M. C., Goan, Y. G., and Lee, H. (2010). cIAP2 upregulated by E6 oncoprotein via epidermal growth factor receptor/phosphatidylinositol 3-kinase/AKT pathway confers resistance to cisplatin in human papillomavirus 16/18-infected lung cancer. Clin. Cancer Res. 16, 5200-5210.

Yuan, H., Fu, F., Zhuo, J., Wang, W. Nishitani, J., An, D. S., Chen, I. S. and Liu, X. (2005). Human papillomavirus type 16 E6 and E7 oncoproteins upregulate c-IAP2 gene expression and confer resistance to apoptosis. Oncogene 24, 5069-5078.

Zur Hausen, H. (2002). Papillomaviruses and cancer: from basic studies to clinical application. Nat. Rev. Cancer 2, 342-350.

Conflict of Interest Statement: The authors declare that the research was conducted in the absence of any commercial or financial relationships that could be construed as a potential conflict of interest.

Received: 15 February 2012; paper pending published: 15 March 2012; accepted: 27 March 2012; published online: 11 April 2012.

Citation: Kostareli E, Holzinger D and Hess J (2012) New concepts for translational head and neck oncology: lessons from HPV-related oropharyngeal squamous cell carcinomas. Front. Oncol. 2:36. doi: 10.3389/fonc.2012.00036

This article was submitted to Frontiers in Head and Neck Cancer, a specialty of Frontiers in Oncology.

Copyright (c) 2012 Kostareli, Holzinger and Hess. This is an open-access article distributed under the terms of the Creative Commons Attribution Non Commercial License, which permits noncommercial use, distribution, and reproduction in other forums, provided the original authors and source are credited. 